\title{
Por um ensino de História que faça sentido: análise das concepções de história de alunos do Ensino Médio
} Toward a History Teaching that Makes Sense: Analysis of
History Conceptions of Students of High School

Ana Paula Rodrigues Carvalho*

\section{RESUMo}

O artigo debate os sentidos da história com base no conceito de consciência histórica de Jörn Rüsen: a interpretação sobre a experiência temporal pode ser mobilizada de modo a entender o presente e projetar o futuro. O ensino de história é essencial, pois o conhecimento sobre o passado atua como fator de orientação temporal na vida prática. Com essa premissa, 82 alunos do Ensino Médio da cidade de Guarapuava (PR) foram questionados a respeito de suas concepções de história. A metodologia empregada utilizou critérios da grounded theory, no que diz respeito a modalidade de recolha e categorização das narrativas. Concluiu-se que a concepção de história dos participantes permanece ancorada em uma ideia de história responsável pelo estudo do passado, sem nenhum tipo de vínculo com questões presentes ou futuras. Embora estejam constantemente mobilizando saberes provenientes de sua experiência temporal, a maioria dos alunos não percebe os sentidos da história na sua vida prática.

Palavras-chave: ensino de história; aprendizagem histórica; consciência histórica.

\section{Abstract}

The article discusses the meanings of history based on the concept of historical consciousness of Jörn Rüsen: the interpretation of temporal experience can be mobilized in order to understand the present and project the future. The teaching of history acquires essential value, since knowledge about the past acts as a factor of temporal orientation in practical life. From this premise, 82 High School students from Guarapuava (PR) were questioned about their conceptions of history. We concluded that the participants' conception of history remains still anchored in an idea of history responsible for the study of the past and without any kind of link with present or future issues. While most of these students are constantly mobilizing knowledge from their temporal experience, they do not realize the meanings of history in their practical life.

Keywords: history teaching; historical learning; historical consciousness.

\footnotetext{
* Universidade Federal do Mato Grosso (UFMT), Cuiabá, MT, Brasil. carvalhoanapaula14@ gmail.com
} 
Os envolvidos devem, como foi dito, interpretar o evento temporal do seu próprio mundo e de si mesmos para poderem efetuar em vida a sua própria temporalidade e apropriar-se dela. Eles precisam dar-lhe um sentido com o qual se relacionam com ele.

Jörn Rüsen

Este artigo tem por objetivo analisar as concepções de história entre alunos do Ensino Médio de dois colégios estaduais da cidade de Guarapuava, Paraná. A pertinência de tal investigação é calcada na necessidade de enfatizar a validade do conhecimento histórico e, por consequência, a sua função de orientação na práxis. Frente à crescente onda de pós-verdade que ameaça a argumentação lógica e o diálogo livre, igualitário e baseado em razões da esfera pública, entender o que é história e as suas vinculações com a vida prática nunca foi tão urgente para aqueles preocupados com o ensino de história.

A primeira parte deste trabalho se volta para a discussão teórica acerca da objetividade e da narratividade na ciência histórica. Em contraposição ao ceticismo e ao relativismo pós-moderno, que prega a dissolução dos sentidos na história, ressalta-se aqui sua função social e sua capacidade de fornecer orientação para a vida prática. Na segunda parte são analisadas as ideias históricas apresentadas pelos alunos em resposta às questões "O que é história?" e "Como o historiador escreve a história?".

De acordo com Jörn Rüsen, toda ação humana é pautada pela sua relação com o tempo. Ao tecerem suas histórias, os homens não o fazem de maneira instantânea ou completamente inédita, mas sob circunstâncias e possibilidades atreladas ao passado. Os seres humanos precisam interpretar o mundo ao seu redor e a si mesmos na relação com os outros para poder viver. E eles o fazem por meio da formação de sentido, no qual a interpretação sobre a experiência temporal pode ser mobilizada de modo a entender o presente e projetar o futuro. Não um futuro longínquo ou teleológico, mas um futuro dinâmico, vinculado à sua práxis.

Essa habilidade é definida como consciência histórica e, segundo Jörn Rüsen, é a "soma das operações mentais com as quais os homens interpretam sua experiência de evolução no tempo do seu mundo e de si mesmos, de forma tal que possam orientar, intencionalmente, sua vida prática no tempo" (Rüsen, 
2011, p. 57). De acordo com o autor, a capacidade de orientação temporal é uma característica inata do homem, portanto independe do seu nível de instrução ou compreensão do conhecimento histórico. Isso ocorre porque

A História já está dada na própria subjetividade da consciência histórica, e isso mais do que nos simples resíduos, pois os próprios sujeitos, suas formas reais de vida, não são outra coisa do que o resultado de um longo desenvolvimento temporal. Antes de começar a pensar em História e antes que se desenvolva uma memória sobre ela, ela já está aí - dentro dos próprios sujeitos do pensamento [...] - e essa é uma condição necessária para a construção cultural da orientação - o passado já é presente. (Rüsen, 1998, p. 334)

Essa concepção de uma história que se faz presente na essência humana é análoga aos conceitos de tradição e preconceito de Hans-Georg Gadamer discutidos por Paul Ricoeur. Para Gadamer a tradição se encontra enraizada no ser humano, no sentido de que "a história me precede e antecipa-se à minha reflexão. Pertenço à história antes de ela me pertencer" (Gadamer apud Ricoeur, 2013, p. 116).

Nas ciências do espírito a clivagem sujeito-objeto já não é mais possível. O sujeito também é determinado pelo objeto, e o reconhecimento da dimensão histórica do homem produz uma reviravolta na arte de compreender e reabilita o conceito de preconceito ou pré-compreensão, que passam a figurar não mais como "o polo oposto de uma razão sem pressuposição, mas um componente do compreender, vinculado ao caráter historicamente finito do ser humano" (Ricoeur, 2013, p. 111).

Com base na concepção da Didática da História alemã, o Ensino de História se torna um saber vital e extremamente importante para a formação de sentido. Por meio da consciência histórica o conhecimento sobre o passado atua como um fator de orientação temporal na vida prática. No entanto, Rüsen adverte que a orientação temporal nem sempre ocorre mediante preceitos históricos, pois aspectos como senso comum, preconceitos, sentimentos de pertença e questões identitárias podem interferir nas tomadas de decisão. Para Rüsen, a formação histórica é o meio para garantir que a orientação temporal se baseie em pressupostos históricos. Sendo assim, formação histórica é 
O conjunto das competências de interpretação do mundo e de si próprio, que articula o máximo de orientação do agir com o máximo de autorrealização ou de reforço identitário. Trata-se de competências simultaneamente relacionadas ao saber, à práxis e à subjetividade. [...] A categoria da formação refere-se à vinculação entre saber e agir exigida pela carência de orientação do sujeito agente, pois insere-se na representação do todo que constitui a situação em que o agente deve lidar com seus problemas. (Rüsen, 2010, p. 95)

A formação é uma categoria da Didática da História responsável pela relação entre saberes científicos e seus usos práticos. Segundo Rüsen (2010), a formação histórica possibilita a integração do saber histórico obtido pela pesquisa em saberes históricos relevantes para a práxis e eficazes para orientação. A subjetividade reside não na acumulação de saberes, mas nas formas de lidar com eles e aplicá-los aos problemas de orientação. Trata-se de um processo dinâmico de reelaborar continuamente saberes na orientação da vida prática.

O conceito de aprendizagem de Rüsen se encontra extremamente vinculado à categoria da formação histórica. Segundo o autor, aprender pode ser definido como a "elaboração da experiência na competência interpretativa ativa, e formação histórica não mais é do que uma capacidade de aprendizado especialmente desenvolvida" (Rüsen, 2010, p. 104). Sendo assim, o aprendizado histórico ocorre quando um dado objetivo que ocorreu no passado torna-se subjetivo e em seguida passa a desempenhar um papel no ordenamento interno no sujeito.

De acordo com Koselleck (2006), a convicção sobre os efeitos do conhecimento histórico na vida prática foi dominante desde a Antiguidade e até o século XVIII. No discurso pré-moderno a tarefa principal atribuída à história era fornecer princípios morais capazes de orientar o agir do seu público. Segundo Rüsen, "Esses princípios transformavam a representação do passado em uma mensagem moral, que colocava seus destinatários em condições de compreender e aplicar as regras da vida humana na prática” (Rüsen, 1998, p. 313).

No século XIX, com o surgimento da história como disciplina acadêmica, a cientificidade passou a se identificar com os procedimentos metodológicos de pesquisa, e o componente ligado às funções didáticas da história foram banidos. A história perdeu sua tarefa de orientar e atribuiu-se como objetivo relatar "as coisas como realmente aconteceram". No entanto, como apontado por Rüsen, "o processo de conhecimento da ciência da história está sempre 
determinado, pela relação à aplicação prática, do saber histórico elaborado pela pesquisa e formatado pela historiografia" (Rüsen, 2007, p. 85). Os historiadores com o seu trabalho querem produzir efeitos. Não existe, portanto, uma neutralidade valorativa na produção cientifica, a escrita da história está sempre permeada por questões relacionadas às carências temporais.

Com a virada linguística na segunda metade do século XX a concepção moderna de história passou a ser criticada. Enquanto os historiadores modernos se preocupavam em ressaltar a racionalidade empregada na construção do conhecimento histórico, os críticos apontavam para a necessidade de se voltar para os processos linguísticos necessários para a representação do passado, ocultos sob o manto de cientificidade. Como consequência disso, observou-se uma supervalorização da linguagem, estilos e forma de textos em detrimento do conteúdo expresso na escrita. A história passa a ser considerada, por alguns, apenas como uma narrativa literária ficcional, o que colocou em questão sua pretensão de verdade e objetividade.

Objetividade e narratividade aparecem muitas vezes como componentes que se anulam quando se fala de uma Ciência Histórica. Enquanto a primeira se encontra vinculada a práticas e métodos precisos de investigação que garantiriam um alto grau de validade, a segunda se refere aos princípios e fenômenos linguísticos que compõem a formulação da pesquisa, mais ligada ao campo da interpretação e subjetividade.

Para Hayden White, há uma cisão entre a história e o passado, de modo que não é possível conhecer o passado objetivamente. Segundo ele,

nenhum conjunto dado de acontecimentos históricos casualmente registrados pode por si só constituir uma estória; o máximo que pode oferecer ao historiador são os elementos de estória. Os acontecimentos são convertidos em estória pela supressão ou subordinação de alguns deles e pelo realce de outros, por caracterização, repetição do motivo, variação do tom e do ponto de vista, estratégias descritivas alternativas e assim por diante - em suma, por todas as técnicas que normalmente se espera encontrar na urdidura do enredo de um romance ou de uma peça. (White, 1994, p. 100)

Como o trabalho do historiador é fruto de uma seleção e usa a narrativa como veículo para tecer uma configuração inteligível dos acontecimentos, o autor conclui que toda a escrita da história é poética e retórica por natureza, 
assim como todas as narrativas ficcionais. As narrativas históricas seriam ficções verbais, porque seus "conteúdos são tanto inventados como descobertos, e suas formas têm mais em comum com os equivalentes na literatura do que com os seus correspondentes nas ciências" (White, 1994, p. 98). A narrativa histórica é considerada um discurso não científico, porque não possui

um sistema terminológico-formal para descrever os seus objetos, ao contrário do que sucedeu com a física e a química, são os tipos de discurso figurativo que ditam as formas fundamentais dos dados a serem estudados. Isso significa que a forma das relações que parecerão ser inerentes aos objetos que habitam o campo da realidade foi imposta ao campo pelo investigador no próprio ato de identificar e descrever os objetos que aí descobre. (White, 1994, p. 111-112, grifos nossos)

Sendo assim, seriam as formas do texto ou as figuras de linguagem que dariam estrutura aos conteúdos; estes poderiam ser tanto inventados como comprovados. Por seu caráter interpretativo e imaginativo a história teria mais elementos em comum com a literatura do que com a ciência.

As críticas feitas à história por White e outros linguistas estimularam o debate acerca da natureza da escrita da história até então inexistente no campo. As discussões foram prolíficas por contribuírem para aprofundar questões relativas à epistemologia da disciplina, para superar um empirismo ingênuo e por permitir tratar de questões como objetividade, verdade e narrativa.

Entretanto, a guinada linguística foi também responsável pelo que White definiu como não disconfirmabilidade (nondisconfirmability), que questiona a veracidade da história ao afirmar que qualquer narrativa histórica poderia ser igualmente válida ou igualmente falsa. Esse ceticismo pós-moderno é extremamente perigoso. Se não existe uma única urdidura capaz de dar forma a uma estória, logo várias intepretações e várias verdades são igualmente possíveis. Sem a pretensão de objetividade e verdade a história pode apresentar múltiplas verdades, e ao resvalar em um relativismo cético a história alcança o paroxismo da negação da Historia Magistra Vitae. A história, agora narrativa literária, estaria aberta a todos os sentidos - portanto não teria mais nenhum, perdendo assim sua força de orientação na vida prática.

Em oposição ao ceticismo e ao relativismo pós-modernos, Rüsen defende a ideia de sentido na história ao propor uma teoria narrativa da ciência histórica. Para o autor, é necessário reformular a definição de objetividade histórica de 
modo tal que seja possível atribuir pretensões tipicamente científicas ao conhecimento histórico. É preciso entender que não é possível se anular frente ao passado; toda narrativa histórica carrega consigo critérios de sentido provenientes das carências de orientação cultural da vida prática. Por esse motivo,

a objetividade histórica não exclui os traços coloridos da vida prática na representação histórica, mas pode ser entendida como um princípio pelo qual esses traços são organizados na sua vitalidade. Emoções, imaginação, poder e vontade são elementos necessários da constituição do sentido histórico. (Rüsen, 1998, p. 335)

Rüsen também propõe um modo diverso de considerar a ficcionalidade. A ficção é responsável pelo processo criador de sentido da interpretação histórica. É o que permite que a escrita da história supere a facticidade informativa das fontes. $\mathrm{O}$ conhecimento histórico não resulta apenas da reprodução das informações contidas nos vestígios, mas também da interpretação.

Como aponta Certeau, "a historiografia é uma mistura de ciência e ficção" (Certeau, 2011, p. 48). Assim como Rüsen, o autor declara a importância da ficção para a construção da narrativa histórica por permitir a construção de "sistemas de correlações entre unidades definidas como distintas e estáveis; quando no espaço de um passado, ela faz funcionar hipóteses e regras científicas" (Certeau, 2011, p. 47).

A ficção funciona na história não mais como um cúmulo de falsidades ou algo que necessita ser depurado da narrativa histórica. A ficção passa a constituir o discurso histórico, e isso não significa renunciar aos procedimentos metodológicos. A diferença entre o historiador e o autor literário se encontra na medida em que o historiador em suas narrativas busca uma reconfiguração verdadeira de fatos ocorridos mediante documentação (Certeau, 2011). Sendo assim, ficção e ciência se encontram na narrativa histórica, porque as técnicas de investigação se imbricam com a imaginação histórica.

$\mathrm{Na}$ teoria narrativa da ciência histórica rüseniana, a ficcionalidade e a narratividade apresentam valoração positiva por garantirem que a história exerça sua função social. Conforme Rüsen, a narratividade

mostra que o conhecimento histórico, por intermédio de sua forma narrativa, se encontra numa relação constitutiva com a vida prática e que ele apresenta 
peculiaridades em relação a outros tipos de conhecimento. A interpretação histórica está basicamente comprometida com a seguinte forma: ela deve enquadrar a informação empiricamente segura sobre o passado em uma narração, transformá-la em História. Somente sob essa forma sobre o passado é especificamente "histórica" e somente sob essa forma o conhecimento histórico pode exercer sua função cultural. (Rüsen, 1998, p. 324)

É com base na convicção de que a narrativa histórica é capaz de fornecer orientação na vida prática que a Educação histórica se coloca como objetivo o desenvolvimento da literacia histórica nos alunos. Isto é, que sejam capazes de ler o mundo historicamente de modo a poderem se inserir e atuar na sociedade de forma crítica e autônoma. Segundo Peter Lee, uma das ferramentas necessárias para o desenvolvimento da literacia histórica é a compreensão da disciplina de história. Conforme o autor, é preciso que "os alunos entendam algo do que seja história, como um compromisso de indagação. [...] Isso sugere que os alunos devem entender, por exemplo: como o conhecimento histórico é possível, o que requer um conceito de evidência” (Lee, 2006, p. 116).

Com base nessas ideias, as fontes históricas utilizadas na produção do conhecimento histórico passam a ser vistas não como meros veiculadores de informação, mas como suportes para questionamentos e análise histórica visando interpretações plausíveis sobre o passado. É importante que os alunos entendam que a narrativa histórica não é uma cópia exata do passado, que o conhecimento histórico se dá de forma indireta a partir de vestígios e das inferências elaboradas a partir de sua análise. Para Lee (2006, p. 140), "a compreensão de como as afirmações históricas podem ser feitas, e das diferentes formas nas quais elas podem ser mantidas ou desafiadas, é uma condição necessária para a literacia histórica”.

Outro componente importante para o entendimento da natureza do saber histórico perpassa a compreensão contextualizada das ações dos sujeitos do passado. O que pressupõe o conceito de empatia, enquanto "crenças e valores das pessoas do passado são entendidos como não necessariamente os mesmos que os nossos, e até mesmo considerados estranhos, todavia eles ainda são reconhecidos como inteligíveis e defensáveis em seus próprios termos e ajudam a dar sentido às crenças e valores do presente" (Lee, 2006, p. 145). 
Sendo assim, a compreensão da disciplina de história está intimamente ligada ao próprio oficio do historiador e, portanto, não se resume apenas na memorização de conteúdos sobre acontecimentos e datas do passado. É necessário notar que:

La comprensión histórica implica unos complejos procesos de pensamiento que permitan interpretar esos contenidos (conceptos de primer orden), a través de estrategias propias de la disciplina (conceptos estratégicos o de segundo orden). Para adquirir estas habilidades es necesario la participación de los alumnos en la práctica del historiador. (Gómez et al., 2014, p. 5)

De acordo com o conceito de literacia histórica, a compreensão do conhecimento histórico decorre do desenvolvimento de competências vinculadas à própria epistemologia da história. Conforme Lee, a compreensão histórica é uma forma de ver o mundo, o que implica entender "as ideias-chaves que tornam possível o conhecimento do passado e os diferentes tipos de afirmações feitas pela história, incluindo o conhecimento de como inferimos e testamos as declarações, explicamos eventos e processos e narramos o passado" (Lee, 2006, p. 140).

Os conceitos de segunda ordem ou conceitos meta-históricos permitem a compreensão da construção do saber histórico, ou seja, revelam como se faz a história. São conceitos como evidência, narrativa, explicação, mudança e empatia. Esse tipo de "conocimientos históricos están relacionados con habilidades propias del historiador que se concretan en: la búsqueda, selección y tratamiento de fuentes históricas" (Gómez et al., 2014, p. 9).

Um dos empecilhos para se alcançar a compreensão histórica decorre da pouca importância dada aos conceitos de segunda ordem. Segundo Lee (2006), mesmo com todas as reflexões feitas a respeito, é ainda recorrente pensar a disciplina escolar de história como um emaranhado de informações a serem aprendidas. Versões mais engajadas sobre a aprendizagem histórica chegam a considerar a importância da compreensão histórica, mas não percebem sua relação com os conceitos específicos da disciplina. Para o autor, é como "se as ferramentas mais poderosas disponíveis para as crianças fossem ocultadas ou escondidas delas, e a própria base da 'autonomia' obscurecida” (Lee, 2006, p. 134).

Para que o passado se torne uma ferramenta poderosa de orientação temporal, a compreensão do conhecimento histórico deve estar atrelada a uma 
história substancial. A dicotomia sustentada por ideias que contrapõem conteúdo a conceitos de segunda ordem é prejudicial para consecução da literacia histórica. Como proposto por Lee, a transformação que a literacia proporciona na forma de ver e atuar no mundo ocorre "através e na presença do conhecimento histórico substantivo em que passado e presente não são desvinculados um do outro" (Lee, 2006, p. 146).

A conquista da literacia histórica transforma o modo como o aluno vê o mundo e permite que atue nele de forma consciente. Para Lee, esse deveria ser o objetivo principal do ensino de história. Um ensino capaz de formar jovens engajados e emancipados deve se preocupar em dotá-los de ferramentas conceituais com as quais eles serão capazes de aprender a pensar por si mesmos.

\section{Concepções DE históRia EM ALunos do Ensino Médio}

A partir de pressupostos construtivistas e, mais precisamente, da Educação histórica, buscou-se estabelecer estratégias para conhecer os jovens alunos participantes da pesquisa e suas concepções de história e escrita da história. Participaram do estudo empírico 82 alunos de dois Colégios Estaduais localizados em Guarapuava (PR), que a partir de agora serão definidos como Escola A e Escola B. Todos os jovens participantes do estudo se encontravam no Ensino Médio. Da Escola A participaram alunos do $2^{\circ}$ e do $3^{\circ}$ ano, e da Escola $\mathrm{B}$, alunos do $1^{\circ}$ e do $3^{\circ}$ ano. Todos estudavam no período da manhã. ${ }^{1}$ Para analisar as ideias históricas dos participantes, optou-se em seguir alguns preceitos da metodologia proposta pela grounded theory.

Segundo Kathy Charmaz, a grounded theory pode ser definida como uma metodologia que se baseia em "algumas diretrizes, ainda que flexíveis, para coletar e analisar os dados visando à construção de teorias 'fundamentadas' nos próprios dados" (Charmaz, 2009, p. 15). Na ground theory a teoria é gerada ao longo da pesquisa, conforme os dados são recolhidos e analisados. O procedimento de recolha, análise e codificação dos dados é simultâneo, e à medida que os códigos são identificados as etapas subsequentes da pesquisa de campo são organizadas.

Na teoria fundamentada "a informação é recolhida sem que esteja condicionada por hipóteses ou preocupações teóricas de partida. A análise da informação é praticamente simultânea à sua recolha, o que pressupõe uma reflexão 
sistemática sobre o material que vai recolhendo" (Pais, 2003, p. 88). Os conceitos gerais adotados para organizar a pesquisa inicialmente assumem caráter provisório e podem ser modificados e abandonados caso resultem irrelevantes. Dessa forma, "são os próprios dados que indicam a trajetória a seguir, a pesquisa vai tomando forma conforme a atividade simultânea de coleta e análise de dados vai ocorrendo" (Carvalho, 2017, p. 44-45).

A escolha dessa metodologia se deve à sua flexibilidade, mas também à influência do interacionismo simbólico e da filosofia pragmática presente na base de sua construção. ${ }^{2}$ O legado interacionista é visível na grounded theory por esta considerar "os seres humanos como agentes ativos em suas vidas e em suas esferas de vida, e não como receptores passivos de forças maiores" (Charmaz, 2009, p. 21). A herança pragmática é observável, pois a grounded theory concebe "o desenvolvimento da teoria como uma maneira de conhecer e melhorar o mundo" (Corbin, 2004, p. 12). Dessa forma, a teoria elaborada a partir de dados empíricos torna-se uma forma de providenciar material teórico para promover transformações sociais.

Com essas premissas, a adoção da grounded theory entre os pesquisadores do ensino de história não poderia ser mais pertinente. Não basta mapear as ideias históricas apresentadas pelos alunos, é preciso também ponderar como e sob quais condições essas ideias podem ser transformadas de modo a assumir características cônsonas com a formação de sujeitos críticos e autônomos. Conforme João Pedro da Ponte,

É necessário interpretar o outro, conhecer o seu modo de pensar e sentir, mas é igualmente necessário estudar formas de trabalho conjunto que levem a novos horizontes. Em Educação, o investigador não é apenas um espectador do que se passa no terreno da prática educativa mas também um actor, ao lado de outros actores, na transformação desse terreno e dos próprios participantes. (Ponte, 2009, p. 112)

De forma geral, este estudo foi divido em três etapas, a saber: estudo exploratório, estudo pré-piloto e estudo principal. Neste artigo são apresentadas as análises realizadas durante o estudo exploratório, a partir das respostas obtidas às questões "O que é história?" e "Como o historiador escreve a história?". 
Na primeira questão os alunos definiram o que é história. De acordo com as respostas dadas foram desenvolvidas quatro categorias, com base nos níveis de progressão das ideias dos alunos: "Sem condições de categorização (SCC)", "História tradicional", "História total" e "História passado/presente/futuro". Cada categoria analítica e os seus respectivos subgrupos seguem explanados aqui.

\section{Nível 1 - Sem condições de categorização}

Neste nível encontram-se as narrativas nas quais o núcleo central da resposta pode ser compreendido, mas pela forma como foi redigida e por falta de mais elementos não foi possível inseri-las em outras categorias. É o que se pode notar das narrativas de Adriana, $3^{\circ}$ ano, Escola A, e João, $1^{\circ}$ ano, Escola B. ${ }^{3}$

- É a descoberta dos historiadores que tiveram que obter para entendê-la. (Adriana, $3^{\circ}$ ano, Escola A)

- O registro do tempo. (João, $1^{\circ}$ ano, Escola B)

\section{Nível 2 - História tradicional}

Neste nível de progressão observou-se que a história é concebida como disciplina que se ocupa de fatos já ocorridos. A tônica das respostas recai sobre o passado pelo passado, pois se valoriza este como especificidade da história. Um passado sem relação com o presente ou com o futuro. Na concepção desses alunos a história seria um grande catálogo de acontecimentos que narrariam os fatos mais importantes de cada época, desde suas origens.

Entre os acontecimentos dignos de serem contados percebeu-se uma tendência em se destacar os de cunho político. O passado é percebido como estático e cumulativo, conforme for passando o tempo, mais história existirá. $\mathrm{O}$ passado também é visto como exótico, praticamente um novo mundo. Essa diversidade o mantém relegado ao passado e desvinculado de sentido para o presente ou futuro. Porém, mesmo que não tenha muito a dizer sobre o presente, ele carrega consigo uma carga de fascinação que o torna interessante.

- É um meio de saber como tudo começou, a história do país, as crises que ocorreu durante os tempos e etc. (Matilde, $3^{\circ}$ ano, Escola A) 
- Para mim é um descobrir praticamente um novo mundo, por mais que esses fato já tenham ocorrido, eles me fascinam muito. (Francisco, $2^{\circ}$ ano, Escola A)

- É a ciência que estuda os tempos passados, praticamente tudo que já aconteceu, desde a origem das coisas até os seus desenvolvimentos, história é algo que sempre vai existir, conforme for passando o tempo, mais história existirá. (Íris, $3^{\circ}$ ano, Escola B)

- Que estuda o passado, os fatos importantes de antigamente. (Beatriz, $1^{\circ}$ ano, Escola B)

- É uma disciplina que estuda fatos acontecimentos que marcaram determinada época, em algum lugar. Estuda também a formação das cidades e a política. (Hugo, $3^{\circ}$ ano, Escola B)

Dentro desse nível de categorização encontra-se outro subgrupo. A tônica permanece na história como disciplina que se ocupa do passado, porém para estes alunos o passado é prenhe de lições para o presente e até mesmo o futuro. Os conteúdos advindos da experiência carregariam em seu bojo regras gerais capazes de orientar ações concretas hoje. Como assevera Rüsen, nessa perspectiva a história é concebida

a partir dos inúmeros acontecimentos do passado que transmite, regras gerais do agir. A memória histórica volta-se para os conteúdos da experiência do passado que representam, como casos concretos de mudanças no tempo (no mais das vezes por causadas ações intencionais), regras ou princípios tomados como válidos para toda mudança no tempo e para o agir humano que nela ocorre. (Rüsen, 2010, p. 51)

Essa definição de passado em que a relação passado, presente e futuro é mecânica, foi inserida no nível 1, porque na concepção desses alunos não se verificou uma ideia de ruptura ou permanências entre passado/presente. A concepção de tempo remete a uma ideia de tempo cíclico, a algo que está sendo desenvolvido novamente. Reinhart Koselleck, em sua obra Futuro passado, declara que essa concepção de história "remete a uma possibilidade ininterrupta de compreensão prévia das possibilidades humanas em um continuum histórico de validade geral" (Koselleck, 2006, p. 43).

Conforme Hartog (2003), nessa perspectiva a história estaria fadada a se repetir, e conhecer o passado seria uma maneira de estar preparado para as 
eventualidades futuras. A história estuda o passado, um passado que retorna ao presente e regula o futuro.

- Aquilo que se passou e esta sendo desenvolvido novamente. (Jorge, $2^{\circ}$ ano, Escola A)

- É passado aproveitar nos ensinar. ${ }^{4}$ (Lorena, $2^{\circ}$ ano, Escola A)

Um segundo subgrupo foi identificado nessa categoria analítica. A ênfase permanece na história como uma disciplina que se ocupa de fatos importantes do passado. A história se ocuparia do estudo das antiguidades, da pré-história, de guerras e de outras datas mais importantes. À diferença das outras narrativas apresentadas, neste subgrupo os alunos mencionam o uso de fontes para a construção desse passado. A concepção de fonte apresentada, no entanto, é limitada. Nota-se que a história não deve ser escrita com quaisquer tipos de fontes: estas devem ser verdadeiras, provas reais que comprovam veridicamente que acontecimentos relevantes marcaram um determinado período.

- É o estudo da antiguidade que contém certas histórias com provas reais e algumas que podem ou não ser mito. (Aline, $1^{\circ}$ ano, Escola B)

- É a compreensão dos fatos que marcaram épocas e acontecimentos relevantes que comprovam veridicamente a existência concreta de como se desenvolveu as formas de vida humana. (Edgar, $3^{\circ}$ ano, Escola B)

- História é um conhecimento que estuda as datas mais importantes, períodos, fontes históricas, pré-História, as guerras mais importantes. (Yasmin, $1^{\circ}$ ano, Escola B)

\section{Nível 3 - História total}

As narrativas sobre a disciplina de história dos alunos inseridos nesta categoria compartilham da convicção de que a história tem como principal função o estudo das ações humanas passadas. Nesse caso a ênfase se encontra nos feitos dos homens ao longo do tempo. Os acontecimentos narrados podem ser de grande ou pouca importância. Assim, não somente aspectos de cunho político são considerados temas históricos. Na perspectiva desses alunos a história concentra seus esforços em todos os âmbitos relacionados à vida do homem. Os temas tratados pela história podem ser políticos, sociais, econômicos, 
culturais ou militares. Enfim, na prática a história se ocupa de tudo aquilo que os povos viveram antigamente.

- É o estudo de ações passadas, independentemente de ser de grande ou pouca importancia, ou até mesmo de invenções. (Simão, $3^{\circ}$ ano, Escola B)

- É a ciência que estuda os acontecimentos passados; desde como as pessoas viviam, como era a sociedade, a política, a economia, os direitos, as guerras, cada povo e cada cultura diferente, etc. (Inês, $3^{\circ}$ ano, Escola B)

- É tudo aquilo que os povos viveram antigamente. (Lara, $2^{\circ}$ ano, Escola A)

Nesta categoria analítica emergiram também ideias sobre como a história não se limitaria a estudar fatos passados, mas também atuais. A história seria o estudo que se ocuparia de escrever a história dos acontecimentos da vida desde o passado até os dias de hoje. A tônica permanece centrada nas ações dos homens, mas a história não se limitaria a narrar somente acontecimentos do passado. A menção que se faz ao presente nesse grupo não se pode considerar um avanço teórico satisfatório. A história, assim como no nível anterior, aparece como um grande catálogo de acontecimentos, e nesta categoria o catálogo se estende até a atualidade.

Este nível apresenta uma perspectiva mais sofisticada em relação ao anterior por entender que a história é o estudo do homem no tempo. Aqui, todos os homens são sujeitos da história e todos os aspectos da vida, desde o âmbito político ao cultural, são abarcados pela história.

- São fatos que ocorreram ou ocorre na humanidade, ou seja, é tudo onde um ser está incluído. (Clara, $1^{\circ}$ ano, Escola B)

- É a cultura de povos, tanto atuais como antigos. É onde se discute formas de governo, características de vida e socializações. Pra mim isso é história. (Rute, $1^{\circ}$ ano, Escola B)

- É a matéria que estuda os acontecimentos da vida, estuda o que aconteceu no passado e como foi o desenvolvimento até os dias de hoje. (Alice, $3^{\circ}$ ano, Escola A)

- É a ciência que estuda a história da vida da sociedade, do mundo. Coisa que aconteceu há milhares de anos atrás até os dias de hoje. (Noa, $3^{\circ}$ ano, Escola $\mathrm{A}$ ) 


\section{Nível 4 - História passado-presente-futuro}

A concepção de história dos alunos que se enquadram neste nível se caracteriza por perceber o elo entre passado e presente. O passado forma o presente, mas não no sentido de repetição e sim como processo histórico dotado de rupturas e permanências visíveis no tempo presente. Não se trata de um passado estático e desvinculado das tramas contemporâneas. Ao contrário, pode ser convocado a responder a interpelações do presente. O historiador se volta em direção ao passado, com base nas fontes e referências passadas, em busca de respostas para problemáticas do presente. $\mathrm{Ou}$, como exposto por Marta, para entender as transformações do homem de hoje.

- Entender as transformações do homem de hoje com base nas fontes e referências passadas. (Marta, $1^{\circ}$ ano, Escola B)

Observou-se ainda neste nível de progressão uma menção à relação entre presente, passado e futuro. Segundo a narrativa exposta a seguir, o objeto da história não se limitaria ao estudo de um passado estático, cristalizado e sem nenhum tipo de vínculo ou relevância para o presente:

- O estudo de fatos acontecidos no passado para descobrir a influência deles no presente e no futuro. (Ernesto, $1^{\circ}$ ano, Escola B)

O passado consubstancia o presente e é capaz de engendrar horizontes de expectativas. O referimento ao vínculo existente entre passado e futuro indica uma noção de história que pode ser considerada mais elaborada. A disciplina de história concebida de tal maneira adquire relevância vital ao se tornar uma ferramenta importante de atuação consciente e autônoma para a vida prática do aluno. Para François Dosse (2003), conhecer o passado proporciona uma ação eficaz sobre o presente.

Este subgrupo do nível 4 de explicação remete ao que Rüsen considera como uma constituição genética de tempo. Nessa tipologia o tempo é visto de forma dinâmica como "abertura de perspectivas de futuro, que vão qualitativamente além do horizonte do que se obteve até o momento" (Rüsen, 2010, p. 58). A experiência do passado é dinamizada no presente e engendra novas possibilidades futuras. Como assevera Cerri, as dimensões do tempo são tomadas de 
forma dinâmica, "a vida é orientada de acordo com as perspectivas de mudanças em suas próprias relações e em direção ao futuro, pela possibilidade de exceder as oportunidades que havia no passado" (Cerri, 2011, p. 102-103). O ensino de história ganha sentido ao propiciar a articulação entre saberes e ação. A história não se limita a estudar o passado. Possibilita a compreensão do vínculo significativo existente entre presente, passado e futuro de forma a oferecer orientação para a vida prática fundamentada historicamente. Pois o agir "é um processo em que continuamente o passado é interpretado à luz do presente e na expectativa do futuro, seja ele distante ou imediato" (Cerri, 2011, p. 28-29).

Na segunda questão solicitou-se que os alunos dissertassem sobre o modo pelo qual o historiador elabora a narrativa histórica. Com base nas respostas obtidas foram identificados quatro níveis de progressão: Nível 1 - "Sem Condições de Categorização (SCC)”, Nível 2 - "Erudição", Nível 3 - "Factual/ Documental" e Nível 4 - "Operação historiográfica”.

\section{Nível 1 - Sem condições de categorização}

As narrativas que se encontram nesta categoria apresentaram um nível alto de incoerência com a pergunta proposta, o que dificultou uma análise mais aprofundada da ideia que o aluno tentou expor. Também se inserem nesse nível analítico as narrativas que não forneceram subsídios suficientes para serem inseridas nas demais categorias. Parece que alguns não entenderam a pergunta e deram respostas descontextualizadas. É possível entender, por exemplo, que para Filippa o historiador trabalha com o tempo e a partir do homem. A resposta não está errada, no entanto essa frase não fornece subsídios claros de como esses elementos se inserem no processo de construção do conhecimento histórico. Essas respostas poderiam também assinalar um problema mais grave, que é a dificuldade de leitura interpretativa. A ausência de elementos úteis para aprofundar a concepção de construção do saber histórico ligado ao oficio do historiador é a principal característica das narrativas que se encontram neste nível.

- Ver de sempre matéria bem documentado. (Joyce, $3^{\circ}$ ano, Escola A)

- Como era as coisas e quase tudo que acontece. (Noa, $3^{\circ}$ ano, Escola A)

- Com o tempo e a partir do homem. (Filippa, $1^{\circ}$ ano, Escola B) 
- Escreve de como foi a história de como foi vivido, de como sofreu no país, etc. (Yara, $3^{\circ}$ ano, Escola B)

- De forma que se possa compreender a sociedade mais antiga do que a que estamos. (Matias, $3^{\circ}$ ano, Escola B)

\section{Nível 2 - Erudição}

Neste nível de progressão os alunos inseriram o ofício do historiador no rol dos eruditos. O saber histórico é elaborado a partir de descobertas, leituras, pesquisa bibliográfica, horas de estudos e colaboração com outros supostos historiadores. Conforme Rúbem, $1^{\circ}$ ano, Escola B, o historiador escreve a partir do conhecimento, que ele já tem dentro de sua cabeça. Outros alunos, como Malena e Juan, deram ênfase na questão da descoberta de coisas interessantes e na acumulação de informações por meio dos estudos. O historiador seria um colecionador de estórias, como "o erudito quer totalizar as inumeráveis "raridades" que as trajetórias indefinidas de sua curiosidade lhe trazem" (Certeau, 1982, p. 81). No entanto, como afirma Certeau, "a crônica ou a erudição que se contenta com adicionar particularidades apenas ignora a lei que a organiza" (Certeau, 1982, p. 91). Nenhuma das narrativas do quadro seguinte faz menção ao trabalho metodológico que envolve a construção do conhecimento histórico.

Durval Muniz de Albuquerque, no artigo "Da história detalhe à história problema: o erudito e o intelectual na elaboração e no ensino do saber histórico", disserta sobre a substituição da figura do historiador erudito pela do historiador pesquisador. Citando Alexandre Herculano, historiador português do século XIX, Albuquerque relembra a crítica direcionada a esse tipo de história que "ignorava a investigação e a pesquisa metódica, vivendo da reprodução de convenções e tradições” (Albuquerque Junior, 2004, p. 59).

De acordo com as narrativas destacadas a seguir, o ofício do historiador parece não requerer nenhum tipo de profissionalização ou especialização, a história poderia ser escrita por um aficionado ou um grande leitor:

- Ele primeiro descobria sobre a História e depois que ele descobria tudo ele acha intereçante e escrevia para o povo saber mais sobre o que tinha antigamente. (Mariana, $2^{\circ}$ ano, Escola $\mathrm{A}$ ) 
- Através do conhecimento que foi passado à ele. (Malena, $3^{\circ}$ ano, Escola A)

- Atravéz de muitos anos de estudo, para dai ele poder colocar em prática. (Juan, $3^{\circ}$ ano, Escola A)

- O historiador escreve a partir do conhecimento, que ele já tem dentro de sua cabeça, aí ele escreve e passa seu conhecimento para o seu público. (Rúbem $1^{\circ}$ Ano, Escola B)

- Pesquisando nos livros, perguntando para outros historiadores. (Catarina, $3^{\circ}$ ano, Escola B)

\section{Nível 3 - Factual/Documental}

Neste nível de progressão os alunos ressaltaram a importância das fontes para a construção do saber histórico. Esses alunos entendem que o conhecimento histórico é elaborado a partir de fontes, no entanto a figura do historiador aparece subordinada e até mesmo anulada diante dessas fontes e dos fatos históricos. Essa concepção de escrita da história se encontra em consonância com algumas respostas obtidas na primeira pergunta deste questionário. Essa percepção de escrita da história se assemelha à definição da disciplina de história dada por alguns alunos do nível 2 (História Tradicional), que declararam que a história é construída a partir de fontes verdadeiras.

A concepção do métier do historiador por esses alunos, sob alguns pontos, parece remeter à perspectiva da escola metódica. As respostas reunidas neste nível analítico indicam um verdadeiro culto às fontes. Como observado por Bourdé e Martin (2000, p. 102), “a escola metódica despreza o papel essencial das questões colocadas pelo historiador às suas fontes e louva o apagamento do mesmo historiador por detrás dos textos". Segundo Frederica, $2^{\circ}$ ano, da escola $\mathrm{A}$, o historiador a partir de fontes seguras pode alcançar a verdade. Para Luna, $3^{\circ}$ ano, Escola B, o historiador relata de forma imparcial o que é revelado pelas fontes. Edgar, $3^{\circ}$ ano, declara que o historiador analisa e fala a verdade, transcreve a história com transparência, ou seja, o historiador anula sua subjetividade diante da fonte para fazer emergir a verdade. O bom historiador transcreve com fidelidade o conteúdo das fontes, e somente assim ele estará deixando um legado dentro do ramo histórico. Esse posicionamento foi defendido por Ranke quando declarou que o bom historiador "registra o facto histórico, de maneira passiva, como o espelho reflecte a imagem de um objeto" 
(Martin; Bourdé, 2000, p. 114). Sob essa ótica, para que a história seja considerada legítima é necessária uma cisão completa entre sujeito e objeto, o historiador apenas relata o que os fatos históricos a priori apresentam.

- Pesquisando em fontes seguras, por meios de muitos estudos até chegar a "verda$d e$ ". (Frederica, $2^{\circ}$ ano, Escola A)

- Ele escreve os acontecimentos baseados em "provas" encontradas por ele, que comprovam um devido acontecimento histórico. (Alice, $3^{\circ} \mathrm{ano}$, Escola A)

- Escreve relatando os fatos. (Murilo, $3^{\circ}$ ano, Escola A)

- Por meio de fotos, roupas, objetos, desenhos que é encontrado, e vai dando origem a nossa historia, pessoas que viveram ou que tem parentes que viveram o corrido também são importantes. (Beatriz, $1^{\circ}$ ano, Escola B)

- Relata os acontecimentos de uma forma imparcial; escreve como acontecia, como eram as pessoas, os objetivos, os lugares, a cultura etc. (Luna, $3^{\circ}$ ano, Escola B)

- A partir do momento em que ele analisa e fala a verdade, transcreve a história com transparência, espontaneidade e conhecimento podemos dizer que ele realmente está deixando um legado dentro do ramo histórico, essencial para a vida futura. Fora disso, são meros diplomas sem função diferencial. (Edgar, $3^{\circ}$ ano, Escola B)

\section{Nível 4 - Operação historiográfica}

As narrativas agrupadas nesta categoria demonstraram uma noção mais complexa sobre o processo de escrita da história. De acordo com as respostas obtidas, o oficio do historiador não se restringiria ao ato de relatar o que consta na documentação de forma imparcial. Nas frases do quadro seguinte os alunos fazem menção às fontes, mas também a um trabalho de pesquisa. Apesar de não apresentarem explicitamente em que consiste a atividade de pesquisa, essas respostas foram categorizadas em um nível mais avançado que o Factual/ Documental por darem a entender que a elaboração da narrativa histórica ultrapassa o simples gesto de averiguação da veracidade da fonte e sua transcrição.

- Através dos fatos que ocorrem e por métodos de pesquisa. (Matilde, $3^{\circ}$ ano, Escola A) - Ele busca ir a fundo sobre um assunto em particular, entender primeiro os acontecimentos que marcaram algum acontecimento histórico, para então depois, começar alguma tese ou algo do gênero. (Giacomo, $1^{\circ}$ ano, Escola B) 
Ainda se observou nesse nível de progressão uma noção mais elaborada sobre o oficio do historiador. Para Tomás, a escrita da história resulta da análise realizada pelo historiador a partir das fontes. $\mathrm{O}$ aluno parece entender que toda interpretação historiográfica se relaciona ao sistema de referências do historiador. Entretanto, o aluno parece não resvalar em um relativismo cético ao tornar a afirmar que a história só pode ser escrita com fontes, com documentos, com objetos que provem ela. A existência de diversas teses para um único tema é imputada à análise de cada historiador ou ao lugar social do historiador que "infiltrando-se no trabalho de análise, organizando-o à sua revelia, remete à 'subjetividade' do autor" (Certeau, 1982, p. 66). Conforme Certeau, é em relação ao lugar de referência do autor que "se instauram os métodos, que se delineia uma topografia de interesses, que os documentos e as questões, que lhes serão propostas, se organizam" (Certeau, 1982, p. 66).

- Atraves das fontes históricas, tem a analise de cada historiador, exemplo são as diversas teses para um único tema. Mais a historia so pode ser escrita com fontes, com documentos, com objetos que provem ela. (Tomás, $1^{\circ}$ ano, Escola B)

\section{CONSIDERAÇÕES FINAIS}

A partir da análise das narrativas dos participantes, observou-se que de forma geral, a maioria dos alunos em ambas escolas apresentaram uma visão tradicional de história. O percentual foi maior entre os alunos da Escola A, onde cerca de $83,78 \%$ dos alunos acreditam que a história é uma disciplina que se ocupa do passado, principalmente de acontecimentos políticos, nacionais, militares - em suma, de eventos e personalidades relevantes de cada período.

O percentual de alunos que compartilham uma concepção de história total foi mais equilibrado, 13,51\% de alunos na escola A e 18,18\% de alunos da Escola B. Para esses alunos a história é um grande catálogo que descreve as ações humanas ao longo tempo. Todos os aspectos da vida humana, assim como todos os sujeitos históricos, são objetos para a história. A história seria responsável pela compilação das ações humanas desde tempos antigos até os dias atuais. Tanto no nível 1 quanto no nível 2 a disciplina de história é percebida como desvinculada do presente e sem relevância para a vida prática. Os alunos que mostraram uma concepção cíclica de tempo percebem a história 
como fornecedora de bons exemplos para o presente. No entanto, o presente não é visto como relevante para a construção do passado. O passado existe per se e é preciso apenas conhecê-lo para entender como se comportar quando uma dada situação se repetir.

No nível de progressão "história passado/presente e futuro" encontram-se 20,45\% dos alunos da Escola B. Esses apresentaram uma concepção de história mais complexa. Para eles, a história é uma disciplina útil porque permite entender as transformações da nossa sociedade a partir de referências passadas. Um aluno menciona a relação entre passado, presente e futuro, ao declarar as formas sob as quais o passado influencia o presente e o futuro. Como observou Koselleck,

As condições da possibilidade da história real são, ao mesmo tempo, as condições do seu conhecimento. Esperança e recordação, ou mais genericamente, expectativa e experiência [...] são constitutivas, ao mesmo tempo, da história e de seu conhecimento, e certamente o fazem mostrando e produzindo a relação interna entre passado e futuro, hoje e amanhã. (Koselleck, 2006, p. 308)

Entender que, de fato, o passado molda o presente e o futuro é uma característica essencial para se entender a importância da disciplina de história para a vida prática. Afinal, o conhecimento do passado permite agir de forma eficaz sobre o presente e influi sobre as expectativas que criamos sobre o futuro.

No que diz respeito à concepção que os alunos têm sobre a forma como a narrativa histórica é escrita, observou-se que os de ambas as escolas (Escola A, 37,84\% - Escola B, 59,09\%) se encontram, em sua maioria, no nível Factual. A narrativa histórica resulta das informações que o historiador consegue levantar a partir das fontes. Essa conjectura não é totalmente errada, no entanto é restrita, por não levar em consideração toda a operação historiográfica que sustenta a construção do conhecimento histórico. Para 7 alunos (18,92\%) da Escola A e 4 alunos (9,09\%) da Escola B, a escrita da história é fruto de estudos e leituras por parte do historiador. Em nenhum momento esses alunos consideraram o trabalho metodológico que envolve a escrita da história. Apenas 5,41\% das narrativas da Escola A e 18,18\% da Escola B foram categorizadas no nível SCC. O número de alunos que não responderam a essa questão foi visivelmente maior entre os alunos da Escola A (32,43\% - Escola B, 9,09\%). Em relação ao nível de progressão Operação historiográfica, apenas 2 alunos na Escola A e 2 
da Escola B mencionaram que a construção do saber histórico envolve, além do levantamento de fontes, também um trabalho de pesquisa metodológico. Entre essas respostas apenas um aluno da Escola B atingiu um nível de concepção mais elaborado sobre a escrita da história. $\mathrm{O}$ aluno mencionou que a interpretação das fontes está submetida ao sistema de referências do historiador, o que explica a multiplicidade de narrativas sobre um mesmo tema.

A concepção de história dos alunos participantes permanece ainda ancorada em uma ideia de história responsável pelo estudo do passado e sem nenhum tipo de vínculo com questões presentes ou futuras. Por mais que esses alunos estejam constantemente mobilizando tais saberes, a maioria deles não percebe os sentidos da história na sua vida prática. Em um momento no qual o ensino de história aparece como obsoleto e ameaçado, torna-se imprescindível ressaltar os sentidos da história na nossa prática docente.

\section{REFERÊNCIAS}

ALBUQUERQUE JÚNIOR, Durval Muniz de. Da história detalhe à história problema: o erudito e o intelectual na elaboração do ensino e do saber histórico. Locus revista de história, v. 10, n. 2, p. 53-72, 2004.

CERRI, Luís Fernando. Ensino de história e consciência histórica. Rio de Janeiro: Ed. FGV, 2011.

CERTEAU, Michel de. A escrita da história. Rio de Janeiro: Forense Universitária, 1982.

CERTEAU, Michel de. História e psicanálise: entre ciência e ficção. 2. ed. Belo Horizonte: Autêntica, 2011.

CHARMAZ, Kathy. A construção da teoria fundamentada: guia prático para análise qualitativa. Porto Alegre: Artmed, 2009.

CORBIN, Juliet. "To Learn to Think Conceptually". [Entrevista concedida a] Cesar A. Cisneros-Puebla. Forum - qualitative social research, Berlin, v. 5, n. 3, p. 1-10, 2004.

FERNANDES, Sueli. Práticas de letramento na educação bilíngue para surdos. Curitiba: SEED, 2006.

FISHER, Berenice M.; STRAUSS, Anselm L. George Herbert Mead and The Chicago Tradition of Sociology. Symbolic Interaction, v. 2, n. 2, p. 9-20, 1979.

FISHER, Berenice M.; STRAUSS, Anselm L. The Chicago Tradition and Social Change: Thomas, Park and Their Successors. Symbolic Interaction, v. 1, n. 2, p. 5-23, 1978. 
GÓMEZ, Cosme Jesús; ORTUÑO, Jorge; MOLINA, Sebastián. Aprender a pensar históricamente: retos para la historia en el siglo XXI. Revista Tempo e Argumento, Florianópolis, v. 6, n. 11, p. 5-27, 2014.

KOSELLECK, Reinhart. Futuro passado: contribuição à semântica dos tempos históricos. Rio de Janeiro: Contraponto: PUC-Rio, 2006.

LEE, Peter. Em direção a um conceito de literacia histórica: Towards a concept of historical literacy. Educar, Curitiba: Ed. UFPR, n. Especial, p. 131-150, 2006.

MARTIN, Hervé; BOURDÉ, Guy. As escolas históricas. Trad. Jacyntho Lins Brandão. Lisboa: Ed. Europa-América, 2000.

MARTINS, Carlos Benedito C. O legado do Departamento de Sociologia de Chicago (1920-1930) na constituição do interacionismo simbólico. Sociedade e Estado, v. 28, n. 2, p. 217-239, 2013.

PAIS, M. José. Culturas Juvenis. 2. ed. Lisboa: Imprensa Nacional - Casa da Moeda, 2003.

PONTE, J. Pedro. O interaccionismo simbólico e a pesquisa sobre a nossa própria prática. Revista Pesquisa Qualitativa, v. 1, n. 1, p. 107-134, 2009.

RICOEUR, Paul. Hermenêutica e ideologias. 3. ed. Petrópolis: Vozes, 2013.

RÜSEN, Jörn. História viva. Teoria da história: formas e funções do conhecimento histórico. Brasília: Ed. UnB, 2010.

RÜSEN, Jörn. Narratividade e objetividade na Ciência Histórica. Estudos IberoAmericanos, Porto Alegre, v. 24, n. 2, p. 311-335, 1998.

RÜSEN, Jörn. Razão Histórica. Brasília: Ed. UnB, 2011.

SILVA, Marília da Piedade M. A construção de sentidos na escrita do aluno surdo. São Paulo: Plexus, 2001.

WHITE, Hayden. Trópicos do Discurso: ensaios sobre a crítica da cultura. São Paulo: Edusp, 1994.

\section{NOTAS}

${ }^{1}$ Estas turmas foram selecionadas, primeiramente, porque o critério de seleção previa que elas, no decorrer de sua trajetória escolar, já tivessem estudado o tema fascismo italiano e, não menos importante, porque os professores dessas turmas aceitaram disponibilizar suas aulas para realização da pesquisa.

${ }^{2}$ Sobre a influência do interacionismo simbólico e da filosofia pragmática na Grounded theory ver: FISHER; STRAUSS, 1978; FISHER; STRAUSS, 1979; MARTINS, 2013.

${ }^{3}$ Todos os nomes utilizados são ficcionais. 
${ }^{4}$ Em um primeiro momento, a narrativa dessa aluna foi inserida no nível 1, mas, após conversar com a intérprete de libras da sala, ficou claro que a forma como os alunos com deficiência auditiva se expressam de forma escrita é diferente daquela dos alunos sem deficit auditivo. Segundo Sueli Fernandes, a flexão de tempo e pessoa dos verbos, a ordem das palavras na oração, a concordância nominal ou verbal, não correspondem às regras da língua portuguesa (FERNANDES, 2006, p. 2). Portanto, a frase foi inserida no segundo nível de categorização. Ver também: SILVA, 2001.

Artigo recebido em 3 de abril de 2019. Aprovado em 20 de novembro de 2019. 